\title{
Gender Variation and Expression of Monoecy in Juniperus phoenicea (L.) (Cupressaceae)
}

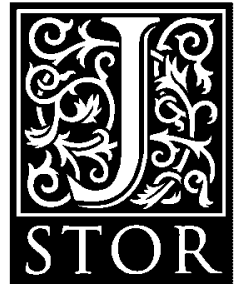

Pedro Jordano

Botanical Gazette, Volume 152, Issue 4 (Dec., 1991), 476-485.

Stable URL:

http://links.jstor.org/sici?sici=0006-8071\%28199112\%29152\%3A4\%3C476\%3AGVAEOM\%3E2.0.CO\%3B2-

Your use of the JSTOR archive indicates your acceptance of JSTOR's Terms and Conditions of Use, available at http://www.jstor.org/about/terms.html. JSTOR's Terms and Conditions of Use provides, in part, that unless you have obtained prior permission, you may not download an entire issue of a journal or multiple copies of articles, and you may use content in the JSTOR archive only for your personal, non-commercial use.

Each copy of any part of a JSTOR transmission must contain the same copyright notice that appears on the screen or printed page of such transmission.

Botanical Gazette is published by The University of Chicago Press. Please contact the publisher for further permissions regarding the use of this work. Publisher contact information may be obtained at http://www.jstor.org/journals/ucpress.html.

Botanical Gazette

(C)1991 The University of Chicago Press

JSTOR and the JSTOR logo are trademarks of JSTOR, and are Registered in the U.S. Patent and Trademark Office. For more information on JSTOR contact jstor-info@umich.edu.

(C2002 JSTOR

http://www.jstor.org/

Mon Mar 25 06:03:37 2002 
Bот, Gaz. 152(4):476-485. 1991.

(C) 1991 by The University of Chicago. All rights reserved.

0006-8071/91/5204-0003\$02.00

\title{
GENDER VARIATION AND EXPRESSION OF MONOECY IN JUNIPERUS PHOENICEA (L.) (CUPRESSACEAE)
}

\author{
PEDRO JORDANO
}

Estación Biológica de Doñana, Apdo. 1056, E-41080 Sevilla, Spain

\begin{abstract}
Variation of gender expression and cone production is described quantitatively for Juniperus phoenicea L. populations in southern Spain and Morocco. The species is monoecious, but most populations showed a dichotomy of gender expression at flowering, with predominantly "male" and predominantly "female" plants and few "monoecious" individuals, a functionally subdioecious breeding system. The proportion of female plants in the Spanish populations ranged from $31 \%$ (R. B. Doñana) to $40 \%$ (Cda. Sabinas, 1988) and did not exceed $10 \%$ in Morocco. Most plants with femaleness values $<.40$ failed to set full-sized seed cones or produced very small crops. Individual plants showed a significant constancy of gender expression in consecutive years. Most inconsistencies in sexual behavior involved transitions between the male and female expressions and their respective "inconstant" conditions. Between-year variations in seed-bearing cone production largely reflected changes in female flowering gender of the individual plants; years with large crop production were characterized by increases in average female gender expression for a given gender category and, as a result, a greater percentage of the population producing female cones. Plants differing in gender expression showed no significant differences in size. Male plants always produced fewer than 10 female cones per crop, and inconstant males rarely exceeded 200 female cones; female plants usually had crop sizes above 100 cones, except in the seasons of cone crop failure. Individual plants also differed in annual shoot growth, but these differences were unrelated to both gender expression and cone production in the previous season. Differences among populations accounted for $52 \%$ of total variance in female cone size, while the effect of the individual plant accounted for $26 \%$; only $22 \%$ was attributable to within-plant variation. A nested model with gender category as the main effect and plant as a nested effect accounted for $88 \%$ of total variation in five cone characteristics, but gender effect accounted for $\leq 2 \%$.
\end{abstract}

\section{Introduction}

Attempts in the past 2 decades to describe quantitatively the expression of gender of higher plants (LLOYD 1972, 1979, 1980b) have revealed an enormous variation frequently hidden within single terms used to qualify breeding systems (monoecy, polygamodioecy, andromonoecy, among others; LLOYD $1980 a$; PRIMACK and LLOYD 1980; LLOYD 1981; GARNOCK-JONES 1986; MCKONE and TONKYN 1986; PrimaCk and MCCALL 1986). Even in monomorphic populations (hermaphrodite, monoecious), a continuum of variation exists between the extremes of functional male and female expressions (LLOYD 1980a; BAWA and WeBB 1984).

The prospective success of the individual plants through pollen and/or seeds depends on both individual and population patterns of parental investment. In the short term, the phenotypic expression of gender depends on the distribution of resources to male and/or female functions in each reproductive episode. Extreme individual variation in these patterns of sex allocation has been documented and reveals a range of potential causes for a lack of consistency in the results obtained so far (GoldmAN and Willson 1986). Thus, selection might be low or nonexistent for a given pattern of sex allocation; variation in gender ex-

Manuscript received March 1991; revised manuscript received July 1991. pression can be constrained by phylogenetic or ontogenetic constraints; or multiple optima can exist due to spatial and/or temporal variation in environmental conditions (GoLDMAN and WILLSON 1986).

Central to the understanding of the selective pressures involved in the evolution of gender expression is the documenting of individual variation in sexual behavior in wild populations. Most studies of gender expression have been limited to one or two reproductive seasons and, therefore, few data are available on the complete (spatial and temporal) patterns of variation in functional gender (but see PRIMACK and MCCALL 1986). Moreover, ecological correlates of gender expression are poorly documented, especially how fecundity correlates with phenotypic gender expression. This information clearly is needed to assess existing models of gender allocation (LLOYD $1980 b, 1984)$.

Diclinous breeding systems, such as dioecy, are frequent among Cupressaceae (GIvNish 1980; DoNOGHUE 1989) and strongly associated to other life-history characteristics. Among European junipers, dioecy is the predominant breeding system; Juniperus phoenicea is the only monoecious species and, presumably, illustrates the primitive condition (RoQues et al. 1984). The few studies attempting to document variation of gender expression in monoecious Cupressaceae (ECKENWALDER 1976; DogRA 1983; LeV-YADUN and LIPHSCHITZ 1987) reveal that patterns of gender 
expression in monomorphic populations are far from cosexual for every individual and frequently depict a subdioecious or paradioecious situation with functional males and females in variable proportions. For example, variation in these proportions ("functional" sex ratio) in Cupressus sempervirens is frequently associated with stress and environmental conditions (FrEEMAN et al. 1981; LEV-YADUN and LIPHSCHITZ 1987) that influence vegetative growth and the pattern of hormonal balance.

The objectives of this study were to document among-population and interannual variation of gender expression in Juniperus phoenicea and to examine its correlates with female fecundity (cone production), characteristics of the female cones, and vegetative growth.

\section{Material and methods}

Production of polliniferous and ovuliferous cones was studied on wild plants in populations of southern Spain and Morocco. Locations, sampling years, and elevations of the Spanish populations follow. The population at Cañada de las Sabinas (Cda. Sabinas, hereafter), Parque Natural de las Sierras de Cazorla, Segura y las Villas, Jaén province (elev. $1,625 \mathrm{~m}$ ), was monitored for $5 \mathrm{yr}$ (1986-90). The population at Cruz de Quique (same general location as the preceding population; elev. 1,215 m) was sampled in 1989 and the Sabinar del Marqués, Doñana Biological Reserve (R. B. Doñana, hereafter), Huelva province population (elev. $16 \mathrm{~m}$ ) in 1986 and 1987. Two Moroccan populations in the Atlas mountains were monitored in 1989, in Imigdal (elev. $1,310 \mathrm{~m}$ ) and Agaiouar (elev. 1,295 m). In addition, cone samples were obtained from a population at Punta del Sabinal (Almería, elev. $12 \mathrm{~m}$ ).

Samples consisted of direct counts of male and female cones in randomly selected branches of 20-50 plants per population. Counts were made during or shortly after the pollination period (midMarch). Usually five branches were counted per plant, and these counts were used in the quantitative estimates of gender variation. In addition to these counts, the relative magnitude of male and female cone production was estimated for each individual. I scored separately the total production of both polliniferous and ovuliferous cones by assigning correlative values from 0 to 5 ( 0 , no cones produced; $1,<10$ cones; $2,10-100$ cones; 3, 100-200 cones; 4, 200-1,000 cones; 5, $>1,000$ cones). These semiquantitative scores were highly correlated $\left(R^{2}=.859\right)$ with the quantitative estimates of gender based on the direct counts and described between-year gender variation in the Cda. Sabinas and R. B. Doñana populations, since counts were not available for all years.

Estimates of functional gender were derived from the expression

$$
G_{i}=\frac{g_{i}}{g_{i}+a_{i} \times E},
$$

where $g_{i}$ is the total number of female cones produced in the counted branches, $a_{i}$ is the number of polliniferous cones, and $E=\Sigma g_{i} / \Sigma a_{i} . E$ is an equivalence factor that equates the probability of androecial units and gynoecial units contributing genes to the next generation (LLOYD 1979, 1980a). By this procedure, $G_{i}$ characterizes the functional "femaleness" of an individual plant. Semiquantitative estimates of $G_{i}$ are derived with the above expression by substituting $a_{i}$ and $g_{i}$ values with the values of the scores for male and female cone production, respectively.

Size of individual plants within randomly located $30 \mathrm{~m} \times 1.5 \mathrm{~m}$ plots was measured (largest two diameters of the crown projection and total height) and the full-sized female cone crop of the previous year was assessed in a semiquantitative scale $(0$, no cone production; $1,<10$ cones; 2 , 10-100 cones; $3,100-200$ cones; 4, 200-1,000 cones; $5,>1,000$ cones). This second count was carried out to estimate the number of full-sized cones before consumption by seed dispersers. Throughout this article all reference to cones will be to female, full-sized, seed-bearing cones just before dispersal unless otherwise stated, when referring to ovuliferous or polliniferous male cones. Exact quantifications of crop size, however, were available for the Cda. Sabinas and R. B. Doñana populations. Full-sized cones were counted during August, just before the dispersal season.

Data on relative shoot growth were obtained for the R. B. Doñada and Cda. Sabinas populations. Five shoots were randomly selected from branches and the growth corresponding to the current season was measured to the nearest millimeter. Measurements were obtained in September each year,when shoot elongation is completed (P. JORDANO, pers. observ.).

Full-sized, mature cones were randomly sampled within each plant to determine maximum cross diameter (diameter, hereafter), number of seeds, total cone dry mass, dry mass of the "pulp," and total seed mass. Individual seed mass was calculated by dividing the total mass of the seeds by the number of seeds. Cone samples were obtained from the populations of Cda. Sabinas, R. B. Doñana, Punta Sabinal, and the two Moroccan sites.

All variables used in statistical analyses were tested for departures from normality and heteroscedasticity. When appropriate, transformations were applied before analyses; otherwise, nonparametric tests were used. Degrees of freedom, expected mean squares, and probability values for ANOVA and MANOVA analyses were estimated with the GLM procedure (SAS 1986; GAGNON et al. 1989). 

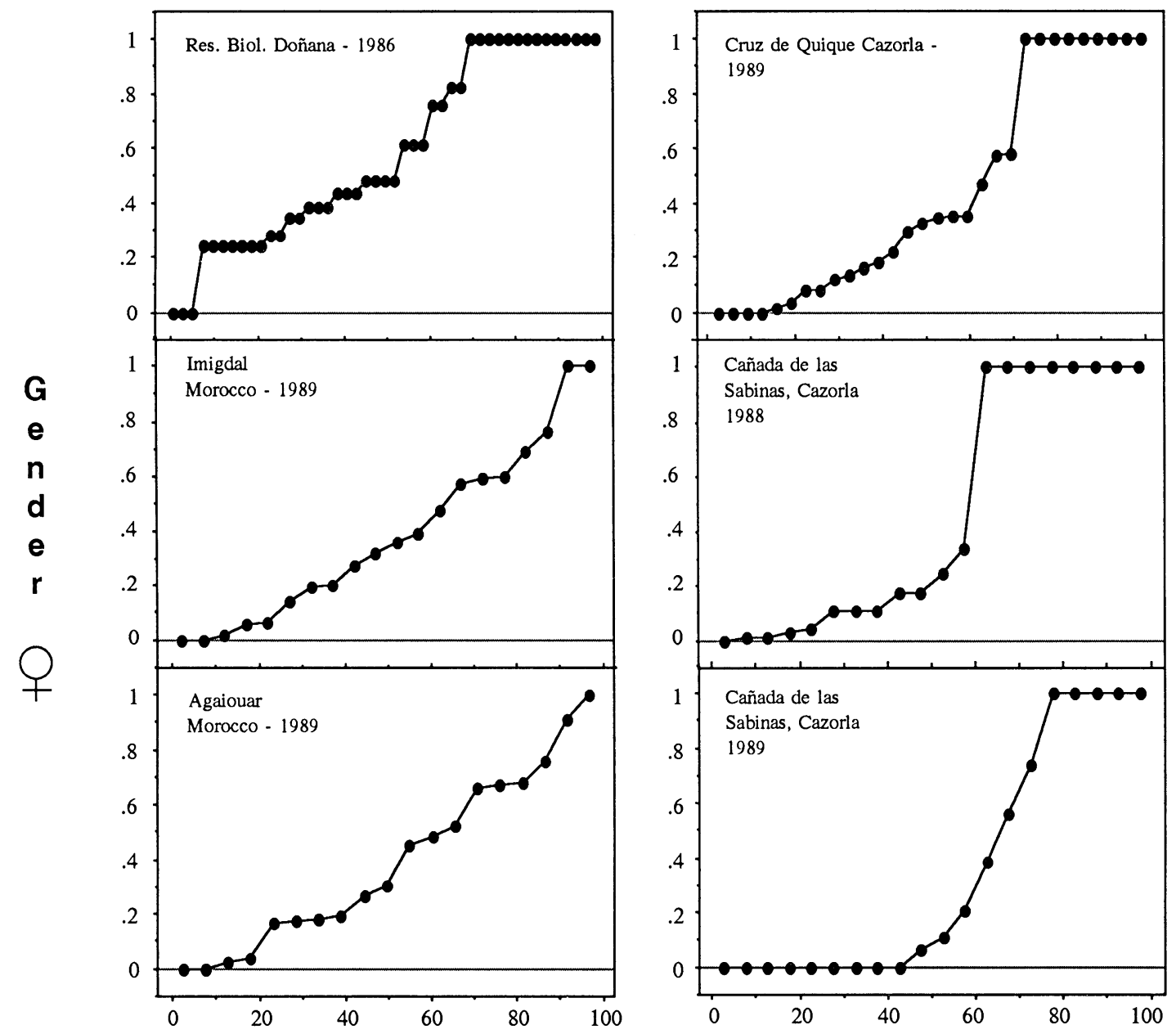

\section{Percentile}

Fig. 1.-Cumulative proportions of individuals (percentile curves) ranked according to female flowering gender (femaleness value, $G_{i}$; see text) in three Spanish and two Moroccan populations of Juniperus phoenicea. The sampling year is indicated. Each point represents a sampled plant, and the percentile associated with each one illustrates the fraction of the population with equal or lower $G_{i}$ value.

\section{Results}

\section{VARIATION OF GENDER EXPRESSION AMONG POPULATIONS}

Percentile curves showing the cumulative proportion of individuals with different female gender values (fig. 1) illustrate ample variation among populations in the distribution of gender. Most populations, however, show a dichotomy of gender expression between predominantly "male" and predominantly "female" plants, with few monoecious individuals. I assigned each sampled plant to a gender category according to the following scale (LLOYD 1981: "male," $G_{i} \leq .20$; "inconstant male," .20<G $\leq .40$; "monoecious," $.40<G_{i} \leq .60$; "inconstant female," $.60<G_{i}$ $\leq .80$, and "female," $.80<G_{i} \leq 1.0$. Frequencies of these gender categories varied significantly among populations $(G=35.16, P \ll .0001)$.
The proportion of female plants in the Spanish populations ranged from $31 \%$ (R. B. Doñana) to $40 \%$ (Cda. Sabinas, 1988) and did not exceed 10\% in Morocco (fig. 1). Proportions of male plants were more similar, usually not exceeding $15 \%$ (see below for between-year variations). Note that all populations had $50 \%$ of the plants, with $G_{i} \leq$ .40. Most of these plants failed to set cones or produced very small cone crops.

Average female gender ranged from $0.586 \pm$ 0.336 (mean, $\mathrm{SD}$ ), $N=45$, in the R. B. Doñana population, and $0.354 \pm 0.433, N=20$, in the Cda. Sabinas (1989) population. There were no significant differences among populations in average gender $(F=1.61, P=.161$, df $=5,148)$. However, when contrasting for differences in average female gender between populations of the different Juniperus phoenicea subspecies, the average female gender of Spanish mountain popu- 


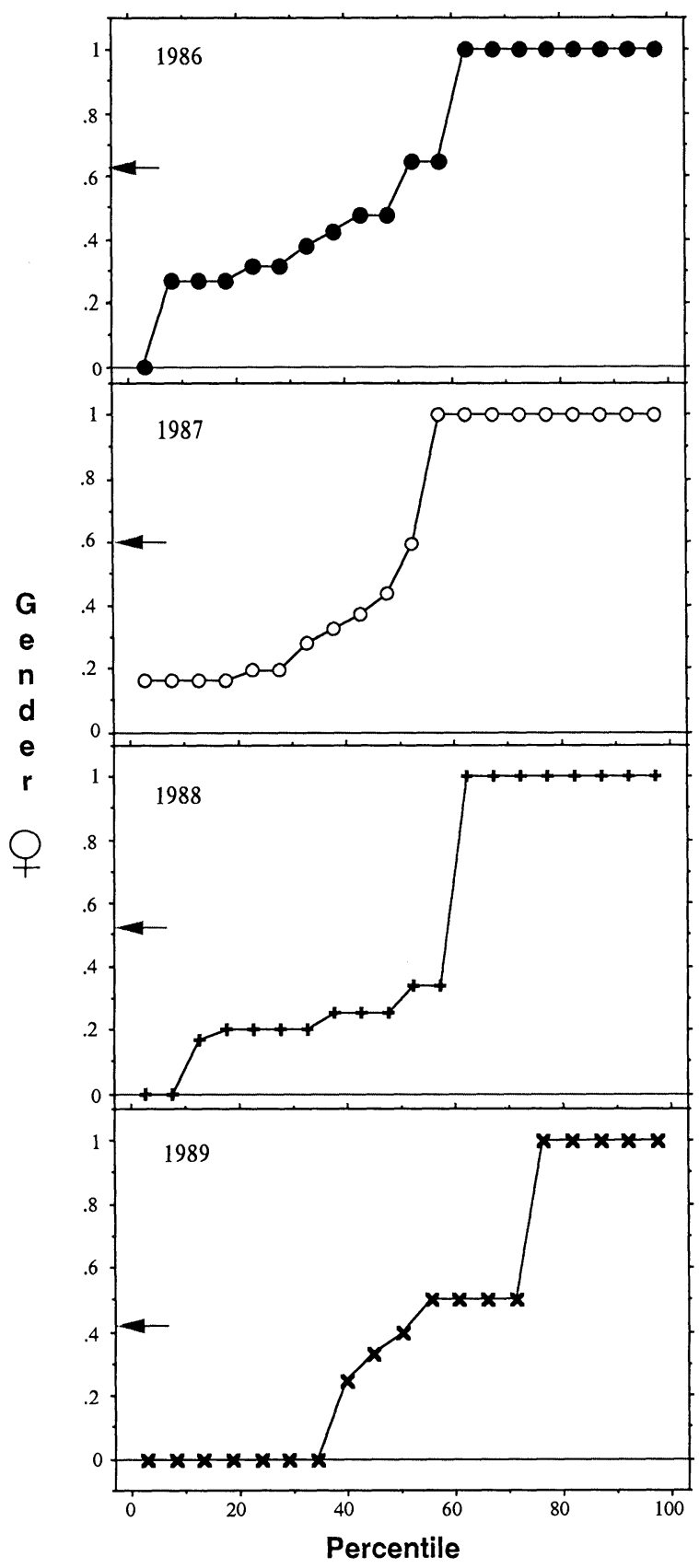

Fig. 2.-Between-year variation in flowering gender (femaleness values obtained from scores; see methods section) in the Cañada de las Sabinas population. Arrows mark the average population gender value in each flowering episode. Curves for 1988 and 1989 differ somewhat from those illustrated in fig. 1 because the former are based on scores of relative flowering intensity rather than direct counts of cone numbers.

lations (nominate phoenicea) differed significantly from the coastal population ( R. B. Doñana, subsp. eumediterranea, var. littoralis $)(F=5.13$, $P=.025)$ and the latter differed significantly from the two Morocco populations (subsp. eumediterranea, var. montana, LEBRETON and THIVEND
1981) $(F=5.65, P=.019)$. Moroccan populations ranked lowest in female gender values, followed by the Spanish mountain and the coastal populations.

Gender variation in the two African populations was continuous along the gradient of functional femaleness, most plants being cosexual. In contrast, the Spanish populations illustrated discontinuous variation in gender expression. The two mountain populations were strongly dimorphic; sizable portions of the individuals behaved as functional males and females.

\section{ANNUAL VARIATION OF GENDER AND FEMALE CONE PRODUCTION}

Information on the between-year consistency in sexual expression was obtained in the Cda. Sabinas population, with records for 1986,1987 , 1988, and 1989 (fig. 2). Individual plants showed significant constancy of gender expression in consecutive years (Kendall coefficient of concordance, $\tau \geq .390, P \leq .005$ for all possible paired comparisons).

For the period 1986-90 I recorded the gender category for each individually marked plant and noted the frequency of transitions between the different categories (table 1). In a total of 67 records, 41 instances $(61.2 \%)$ indicated constancy in sexual expression from one year to the next. Most inconsistencies in sexual behavior involved transitions between the male and female expressions and their respective "inconstant" conditions, i.e., $15(22.4 \%)$ transitions involved changes between categories of the same gender expression. Changes to a different gender were recorded only five times $(7.5 \%)$. Therefore, the population studied showed high constancy in both the quantitative expression of gender and qualitative sexual behavior (male, monoecious, or female).

Considering constancy across the whole 198690 period, a total of six plants $(30 \%)$ behaved constantly as females at Cda. Sabinas. Ten plants $(50 \%)$ behaved as males or inconstant males, showing very low $G_{i}$ values in all years. Only one plant behaved as a female during the first $3 \mathrm{yr}$ and then switched to male in 1989. A constant male sex expression during the successive $4 \mathrm{yr}$ was not recorded, most male plants behaving as inconstant males or "monoecious" in certain years. Thus, the overall pattern was for a much more stable gender expression among female plants.

Extreme variations in the sizes of the cone crops were recorded both among populations and among years within populations (table 2). Preliminary observations from Cda. Sabinas indicated that good cone crops can take place every third year. Thus, in a period of $5 \mathrm{yr}$, only one good crop was recorded in this population. Data from R. B. Doñana indicate that this pattern also oc- 
TABLE 1

FREQUENCIES OF TRANSITIONS BETWEEN CATEGORIES OF GENDER EXPRESSION FOR INDIVIDUAL JUNIPERUS PHOENICEA PLANTS IN CONSECUTIVE YEARS

\begin{tabular}{|c|c|c|c|c|c|}
\hline \multirow[b]{2}{*}{$\begin{array}{l}\text { GENDER EXPRESSION } \\
\text { IN CURRENT YEAR }\end{array}$} & \multicolumn{5}{|c|}{ GENDER EXPRESSION NEXT YEAR } \\
\hline & Male & $\begin{array}{c}\text { Incon- } \\
\text { stant } \\
\text { male }\end{array}$ & $\begin{array}{l}\text { Mono- } \\
\text { ecious }\end{array}$ & $\begin{array}{l}\text { Incon- } \\
\text { stant } \\
\text { female }\end{array}$ & Female \\
\hline Male $\ldots \ldots \ldots$. & 2 & 8 & 0 & 0 & 0 \\
\hline Inconstant male ....... & 6 & 17 & 1 & 1 & 0 \\
\hline Monoecious........ & 0 & 4 & 1 & 0 & 0 \\
\hline Inconstant female & 0 & 0 & 1 & 0 & 1 \\
\hline Female $\ldots \ldots \ldots \ldots$ & 3 & 1 & 0 & 0 & 21 \\
\hline
\end{tabular}

NoTE. - Data for years $1986,1987,1988,1989$, and 1990 have been pooled. Cda. Sabinas population $(N=20$ plants).

curred in the lowlands, where 1986 was a mast year (table 2 ) and then a good crop was produced in 1989 (P. JORDANO, pers. observ.).

"Femaleness," estimated quantitatively, was positively and significantly correlated with the number of full-sized cones in those populations with several years of data $\left(r_{s} \geq .4702, P \leq .045\right.$, $N=20$ for the correlations between individual $G_{i}$ values and cone crop sizes of $1986,1987,1988$, 1989 , and 1990 in Cda. Sabinas; $r_{s}=.4624, P=$ $.002, N=45$ for the correlation between $G_{i}$ values and cone crop sizes of 1986 and 1987 in R. B. Doñana). Thus, between-year variations in cone production largely reflected changes in "femaleness" of the individual plants. Years with production of large crops were characterized by in- creases in production of ovuliferous cones. As a result, a greater percentage of the population produced cones in these mast years.

\section{ECOLOGICAL CORRELATES OF GENDER VARIATION}

Gender variation was not consistently associated with differences in plant size; different gender categories showed no significant heterogeneity in plant height and diameter of horizontal crown projection (Wilk's $\lambda=.936, F=.959, P$ $=.469, \mathrm{df}=8,228)$.

To evaluate relationships between "femaleness," estimated quantitatively, and production of full-sized cones, I compared $G_{i}$ values or gender categories for a given year with the number

TABLE 2

SUMMARY OF FULL-SIZED FEMALE CONE CROP SIZES IN SEVERAL JUNIPERUS PHOENICEA POPULATIONS AND YEARS

\begin{tabular}{|c|c|c|c|c|c|c|c|c|c|}
\hline \multirow{2}{*}{$\begin{array}{c}\text { POPULA- } \\
\text { TION } \\
\text { AND YEAR }\end{array}$} & \multirow[b]{2}{*}{$N$} & \multirow[b]{2}{*}{$\begin{array}{l}\text { MEDIAN } \\
\text { CROP SIZE }\end{array}$} & \multirow[b]{2}{*}{ RANGE } & \multicolumn{6}{|c|}{ FREQUENCY OF FEMALE CONE CROP SIZES } \\
\hline & & & & 0 & $<10$ & $10-100$ & $\begin{array}{c}100- \\
200\end{array}$ & $\begin{array}{c}200- \\
1,000\end{array}$ & $>1,000$ \\
\hline \multicolumn{10}{|l|}{ Cda. Sabinas: } \\
\hline $1986 \ldots \ldots$ & 20 & 13 & $0-375$ & 7 & 3 & 5 & 3 & 2 & 0 \\
\hline 1987 & 20 & 4 & $0-280$ & 9 & 4 & 5 & 1 & 1 & 0 \\
\hline 1988 & 20 & 1,053 & $0-19,750$ & 0 & 0 & 4 & 0 & 5 & 11 \\
\hline 1989 & 20 & 11 & $0-1,670$ & 9 & 1 & 1 & 1 & 5 & 3 \\
\hline $1990 \ldots \ldots$ & 20 & 3 & $0-106$ & 15 & 1 & 3 & 1 & 0 & 0 \\
\hline \multicolumn{10}{|l|}{ R. B. Doñana: } \\
\hline $1986 \ldots \ldots$ & 50 & 1,765 & $0-21,250$ & 2 & 1 & 5 & 3 & 6 & 33 \\
\hline $1987 \ldots \ldots$ & 50 & 72 & $0-2,977$ & 1 & 6 & 24 & 9 & 8 & 2 \\
\hline \multicolumn{10}{|l|}{ Cruz de Quique: } \\
\hline \multicolumn{9}{|l|}{ Imigdal: } & 3 \\
\hline $\begin{array}{l}1989 \ldots \ldots \\
\text { Agaiouar: }\end{array}$ & $\cdots$ & $\cdots$ & $\cdots$ & 3 & 6 & 5 & 2 & 3 & 1 \\
\hline $1989 \ldots \ldots$ & $\cdots$ & $\cdots$ & $\cdots$ & 7 & 8 & 2 & 2 & 1 & 0 \\
\hline
\end{tabular}

NotE.-Direct counts of cone crop sizes in Cruz de Quique, Imigdal, and Agaiouar populations were not available. 


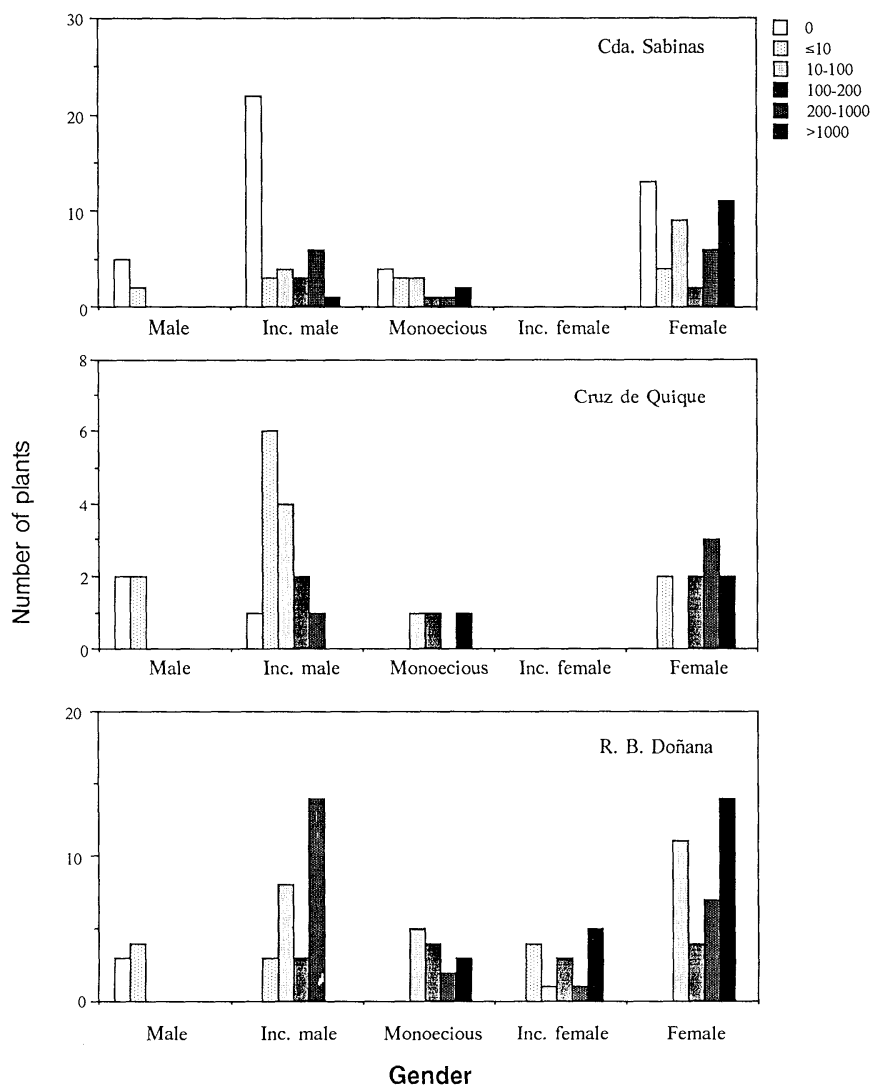

FIG. 3.-Frequency distribution of female cone crop sizes (number of full-sized cones per crop; six categories with different shadow patterns) for Juniperus phoenicea plants, differing in gender expression, in three Spanish populations. No inconsistent female plants were present in the Cda. Sabinas and Cruz de Quique populations (see fig. 1).

of full-sized cones in the following year, since cone growth extends over $1.5 \mathrm{yr}$ in these populations (P. JoRDANO, pers. observ.). For the populations with data available for several years, cone production varied significantly with gender expression $(F \geq 4.96, P \leq .01$, for all the comparisons in Cda. Sabinas, and $F \geq 3.26, P \leq .019$ for all the comparisons in R. B. Doñana). The contrasts between "male" gender categories (both males and inconstant males) and the "female" categories (both inconstant females and females) always yielded significant results, with male gender expression associated with smaller cone crop sizes $(F \geq 5.45, P \leq .024$, in all possible comparisons).

Male plants always produced fewer than 10 cones per crop, and crop sizes of inconstant males rarely exceeded 1,000 cones (fig. 3). In contrast, female plants usually had crop sizes above 100 cones, except in the seasons of cone crop failure (Cda. Sabinas, 1986 and 1990). The pooling of data from several reproductive seasons masked between-gender differences in crop size (fig. 3, Cda. Sabinas and R. B. Doñana populations) largely because female and inconstant female plants showed extreme variations in crop sizes associated with alternative bearing and masting behavior. For example, some inconstant males produced large crops in Cda. Sabinas in the mast year of 1988 .

In summary, gender variation is not related to plant size, but individual plants show high consistency in gender expression from year to year. The relative position of individual plants in the femaleness gradient of the population is maintained in consecutive years, but the absolute number of ovuliferous cones produced changes, resulting in great variations of the cone crop at the population level.

Differences in vegetative growth among individual plants were highly significant $(F \geq 5.80$, $P=.0001$, for 1986,1987 , and 1988) but were independent of the plant's gender $(F<1.50, P$ $\geq .200$, for these $3 \mathrm{yr}$ ) (table 3 ). Correlations between vegetative growth in a given year and number of cones produced in the previous year were insignificant also $\left(r_{s} \leq-.239, P>.15\right.$, in all the comparisons for $1986,1987,1988$, and 1989). This indicates the absence of significant short-term trade-offs between reproduction and subsequent vegetative growth in this species, annual shoot elongation being largely independent 
TABLE 3

Average ANNUAL SHOOT GROWTH OF INDIVIDUAL JUNIPERUS PHOENICEA PLANTS DIFFERING IN GENDER EXPRESSION

\begin{tabular}{|c|c|c|c|}
\hline \multirow[b]{2}{*}{ YEAR } & \multicolumn{3}{|c|}{ GENDER EXPRESSION ${ }^{a}$} \\
\hline & $\begin{array}{l}\text { "Male" } \\
(N=20)\end{array}$ & $\begin{array}{c}\text { "Monoecious" } \\
(N=24)\end{array}$ & $\begin{array}{l}\text { "Female" } \\
(N=36)\end{array}$ \\
\hline \multicolumn{4}{|l|}{$\begin{array}{l}\text { Average annual shoot } \\
\text { growth }(\mathrm{mm}) \text { : }\end{array}$} \\
\hline $1986 \ldots \ldots \ldots$ & $17.5 \pm 5.2$ & $15.5 \pm 4.0$ & $16.9 \pm 6.8$ \\
\hline 1987 & $21.7 \pm 8.0$ & $24.6 \pm 7.9$ & $25.2 \pm 13.2$ \\
\hline \multirow[t]{3}{*}{1988} & $37.1 \pm 10.5$ & $36.4 \pm 9.7$ & $39.3 \pm 16.9$ \\
\hline & \multicolumn{3}{|c|}{ YEAR $^{\mathrm{b}}$} \\
\hline & 1986 & 1987 & 1988 \\
\hline \multicolumn{4}{|l|}{ Summary of effects: } \\
\hline Gender expression & $1.50^{\mathrm{NS}}$ & $1.46^{\mathrm{NS}}$ & $1.24^{\mathrm{NS}}$ \\
\hline Plant (gender) ${ }^{c} \ldots$ & $6.27 * * *$ & $5.87 * * *$ & $11.03^{* * *}$ \\
\hline Shoot ........ & $1.53^{\mathrm{NS}}$ & $0.32^{\mathrm{NS}}$ & $2.79 *$ \\
\hline
\end{tabular}

a "Male" category groups both male and inconstant male; "female" category groups both inconstant female and female.

${ }^{\mathrm{b}} F$ values and associated probability for a nested ANOVA model with the type of gender expression as the main effect and individual plant as a nested effect with shoot as a repeated measure (five shoots measured per plant). See methods section. ${ }^{*} P<.05 ;{ }^{* * *} P<.01 ;$ NS $=$ not significant.

${ }^{\mathrm{C}}$ Plant nested within gender expression.

of gender expression and cone production in the previous season.

Data on cone characteristics were available for three Spanish populations (Cda. Sabinas, Punta Sabinal, and R. B. Doñana), and information on cone diameter was also available for the two African populations (Imigdal and Agaiouar). Cone size (maximum cross diameter) differed significantly among populations and among plants within populations $(F=77.10, P=.0001, \mathrm{df}=$ $77,2325)$. These two effects accounted for $84.8 \%$ of variation in cone size, and individual plants showed a significant added effect over the site effect $(F=36.29, P=.0001)$. However, the population effect accounted for $51.9 \%$ of total variance, while the effect of the individual plant ac- counted for $25.6 \%$; only $22.4 \%$ was attributable to within-plant variation. Cones of the two Moroccan populations were significantly larger (means of 10.4 and $10.5 \mathrm{~mm}$ for Agaiouar and Imigdal, respectively) than those from the Spanish populations $(10.1,9.4$, and $7.8 \mathrm{~mm}$ for R. B. Doñana, Punta Sabinal, and Cda. Sabinas, respectively) (Scheffe's $S, P<.05$ ). Differences among the Spanish populations were also significant, cones of the two lowland populations being larger than the mountain population.

Variation in cone characteristics was examined in the three Spanish populations. Most variation in the five measured traits was accounted for by the population effect $(>60 \%)$, with the exception of number of seeds per cone, that showed most

TABLE 4

CHARACTERISTICS OF JUNIPERUS PHOENICEA CONES FROM INDIVIDUAL PLANTS OF DIFFERENT GENDER EXPRESSION

\begin{tabular}{cccc}
\hline \hline & \multicolumn{3}{c}{ Gender EXPRESSION } \\
\cline { 2 - 4 } & "Male" & "Monoecious" & "Female" \\
VARIABLE & $(N=123)$ & $(N=84)$ & $(N=406)$ \\
\hline Cone diameter $(\mathrm{mm}) \ldots \ldots \ldots$ & $9.2 \pm 1.2^{\mathrm{a}}$ & $9.6 \pm 1.2^{\mathrm{ab}}$ & $9.6 \pm 1.2^{\mathrm{b}}$ \\
Cone dry mass $(\mathrm{mg}) \ldots \ldots \ldots \ldots$ & $351.9 \pm 161.2^{\mathrm{a}}$ & $431.4 \pm 186.5^{\mathrm{b}}$ & $393.8 \pm 178.1^{\mathrm{ab}}$ \\
Dry mass of seeds $(\mathrm{mg}) \ldots \ldots \ldots$ & $79.9 \pm 40.7^{\mathrm{a}}$ & $96.9 \pm 45.3^{\mathrm{b}}$ & $84.7 \pm 39.7^{\mathrm{a}}$ \\
Seed dry mass $(\mathrm{mg}) \ldots \ldots \ldots \ldots$ & $17.1 \pm 9.5^{\mathrm{a}}$ & $17.0 \pm 8.5^{\mathrm{a}}$ & $15.5 \pm 7.4^{\mathrm{a}}$ \\
Number of seeds per cone $\ldots \ldots$ & $5.1 \pm 1.6^{\mathrm{a}}$ & $6.3 \pm 1.8^{\mathrm{b}}$ & $5.8 \pm 1.5^{\mathrm{c}}$ \\
\hline
\end{tabular}

NoTE. - "Male" category groups both male and inconstant male plants; "female" category groups both inconstant female and female plants. $N=613$ cones; data from Cda. Sabinas and R. B. Doñana populations pooled. Entries sharing the same superscript do not differ significantly (Scheffe's $S, P<.05$ ). 
TABLE 5

SUMMARY OF NESTED ANOVA ANALYSES FOR CONE CHARACTERISTICS WITH GENDER EXPRESSION AS THE MAIN EFFECT AND PLANT INDIVIDUAL AS A NESTED EFFECT

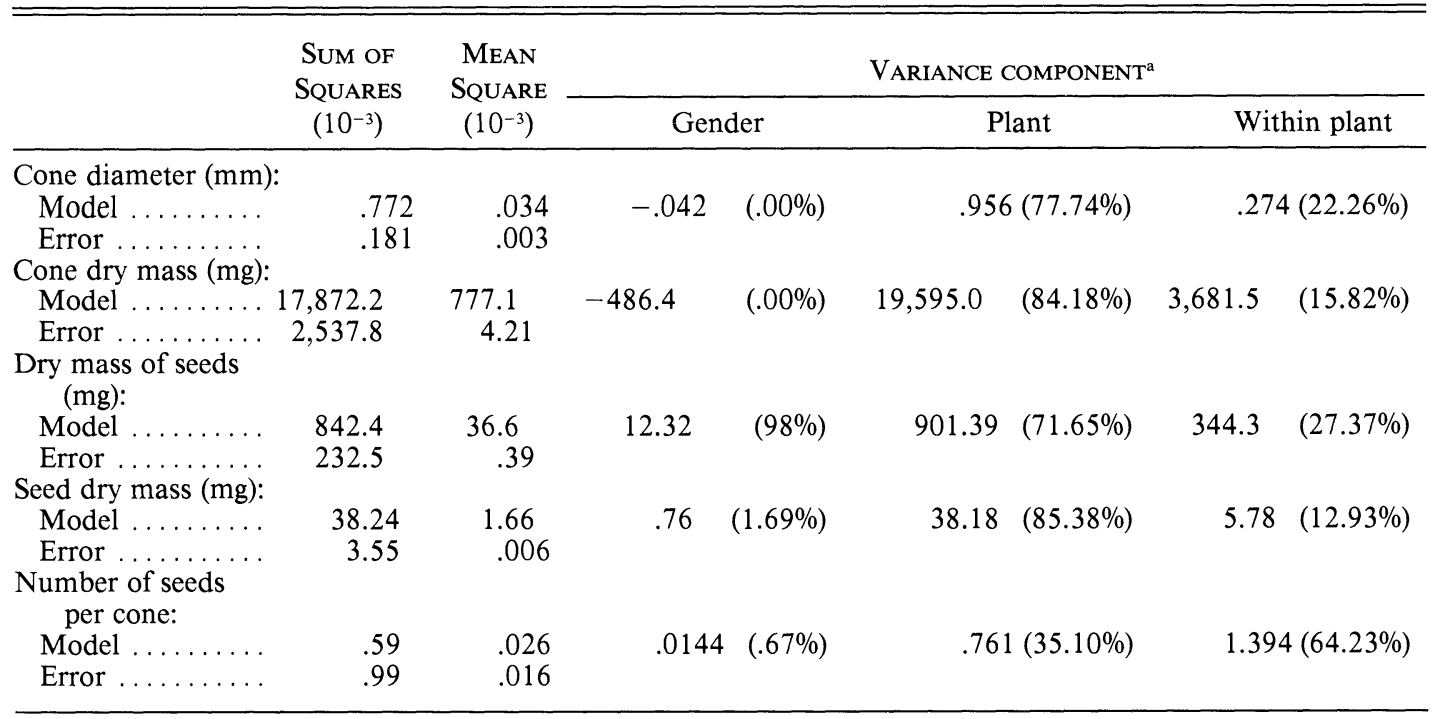

a Variance components and percentage of total variance for each effect.

variation within plants. Gender expression had a highly significant effect on cone characteristics (table 4), but this seemed attributable to variation among individual plants and not to a direct consequence of gender differences. Thus, a nested model with gender category as the main effect and plant as a nested effect (Cda. Sabinas and R. B. Doñana populations pooled) accounted for $87.6 \%$ of total variation in cone characteristics, but gender effect accounted for $\leq 2.0 \%$ of variation and the plant effect accounted for $\geq 75 \%$ of the total variation, with the exception of number of seeds per cone (35.1\%) (table 5). Therefore, most observed variation in cone characteristics was attributable to population provenance, with an added effect due to among-plant variation within population; however, only a negligible fraction of this variation among plants was attributable to gender expression.

\section{Discussion}

Quantitative estimates of functional gender have been extremely useful in characterizing the sexual phenotype of individual plants. By describing gradients between functional "femaleness" and "maleness" and locating each individual of the population along them, multimodal distributions of gender expression have been found in monoecious and gyno- and andromonoecious species (LLOYD 1972; LLOYD et al. 1980; PRIMACK and LlOYD 1980; LLOYD 1981, 1982; Garnock-Jones 1986; PrimaCK and McCALL 1986).
Individuals of the monoecious species Juniperus phoenicea studied here depart from a cosexual expression of gender and illustrate a subdioecious situation. This dimorphic expression of gender is even more marked when estimating the "fruiting" gender (GARNOCK-JONES 1986), since most male or inconstant male plants fail to set full-sized female cones. Abortion of developing female cones usually takes place during the first summer (ca. $3 \mathrm{~mm}$ in diameter) and, in nonmasting years, most inconstant males have no developing cones by October. However, strong variation among populations in the extent of this dimorphism exists. Thus, individuals of the Spanish mountain populations can be readily characterized as either male or female, and a large gap in phenotypic gender exists $\left(.40<G_{i}<.90\right)$. This gap is absent in the lowland and African populations. Between $30 \%$ and $40 \%$ of the individuals in the Spanish populations have totally female gender expression, but less than $10 \%$ do so in Morocco. Proportions of male plants are more similar across populations, not exceeding $15 \%$, but show wide between-year variations.

The constancy in both the quantitative (femaleness values) and qualitative (gender category) expression of gender over $5 \mathrm{yr}$ suggests that genetic differences account for a large fraction of variance in sex expression in J. phoenicea. However, other studies (PRIMACK and MCCALL 1986) have reported considerably higher constancy in gender expression. The relative rank of each individual plant in the population with respect to femaleness value is significantly invariant from 
one year to the next but between-year variations are found, and they suggest that environmental conditions may affect the particular gender allocation in a given season. Plant-specific characteristics can constrain the range of potential variation in gender allocation for a given individual. For example, between-population differences found in this study add to existing differences among infraspecific taxonomic entities described in $J$. phoenicea (LEBRETON and THIVEND 1981; LEBRETON and LARACINE 1982; LEBRETON 1983) and suggest that gender expression reflects local population differentiation. Other studies of monoecious, andromonoecious, or "polygamodioecious" species (PRIMACK and LLOYD 1980; LLOYD 1981; PRIMACK and MCCALL 1986) have found a similar pattern of betweenyear constancy in gender expression with variable amounts of environmental influence. Future studies of gender variation should attempt to dissect these two components of variance by explicitly considering phenotypic gender as an additional quantitative trait of the individual plant (LlOYD 1980a).

Realized fecundity, in terms of full-sized seeds available for dispersal, is strongly correlated with the expression of femaleness. Male or inconstant male plants produce some ovuliferous cones in certain years, but these rarely develop to fullsized cones. This, and the finding of a marked dimorphism in sexual behavior at flowering, indicates that differential allocations to paternal and maternal functions occur at cone initiation. Postpollination reductions of initiated cones, either because of lack of fertilization of sufficient number of ovules per cone (OwENs et al. 1990) or damage by insect seed predators (RoQUES et al. 1984; FERNANDES and WHITHAM 1989) merely amplify this differential. This situation contrasts with other species (Artemisia vulgaris; GARNOCKJONES 1986) that regulate maternal investment by post-anthesis reductions of fruit set and fruit abortion.

The extreme between-year variation in cone production at a population level observed in this study is a result of (1) plants that regularly behave as female increasing the number of ovuliferous cones in certain (mast) years and (2) plants that regularly behave as male (not producing ovuliferous cones) setting some seed cones (usually no more than 10 cones) in good crop years. As a result, during a mast year a greater portion of the population produces full-sized cones, and average crop sizes increase.

I found no evidence of significant short-term trade-offs between cone and seed production and vegetative growth in subsequent seasons. Vegetative growth was unrelated to both gender expression and cone production in the previous season. Other studies have failed to find trade-offs between growth and reproduction (PRIMACK and LLOYD 1980); in other cases, the effect of gender expression or sex was not corrected for correlated effects of other variables such as plant size, age, and microsite conditions. Most likely, short-term variation in vegetative growth relative to reproductive output in immediate years was dampened by long-term effects in a long-lived perennial such as $J$. phoenicea. The results showed that significant between-plant heterogeneity in growth existed, but it was totally independent of gender allocation.

Characteristics of the cones (size, number of seeds, seed size) were extremely variable among the populations studied and showed additional variation among individual plants. Most variation, however, was accounted for by the provenance effect. These differences illustrate variation specific to the different subspecific taxa sampled (LEBRETON 1983). Individual gender variation accounted for a negligible fraction of the plant-specific variance in cone characteristics.

Male plants had smaller cones and fewer seeds per cone than monoecious or female plants. Selffertilization in $J$. phoenicea, as in many other Cupressaceae and gymnosperms (OwENs and Molder 1980; Dogra 1983; Allison 1990; OwENS et al. 1990), may result in decreased seed set and smaller cone size relative to cross-fertilization. The thorough abortion of the small cone crops initiated by male $J$. phoenicea plants may thus reflect extensive self-fertilization, contrasting with the predominantly outcrossed paternity of the female and inconstant female crops.

The results of this study emphasize the need for long-term data on gender variation in natural populations and demonstrate a continuum of variation in gender expression within populations. Application of gender models demonstrated a subdivision of the populations in distinct gender types that appear fairly consistent from year to year. Categorizing gender expression therefore ignores biologically relevant variation that needs consideration in studies of the evolution of sex expression.

\section{Acknowledgments}

I am most grateful to M. CARRION for his skillful assistance during field and laboratory work. Without his help this study would not have been achieved. Financial support came from C.I.C.Y.T. and Junta de Andalucía. The final part of the field work and preparation of the manuscript were funded by D.G.I.C.Y.T., project PB87-0452. Early work was funded by a postdoctoral grant, Spanish C.S.I.C. I sincerely appreciate the logistic assistance and permission to work in Cazorla extended to me by the Agencia de Medio Ambiente, Junta de Andalucía, particularly the Cazorla Of- 
fice. The project benefited from the agreement between the Spanish C.S.I.C. and Agencia de Medio Ambiente. Over the years, J. A. Amat, M. Carrion, M. Cobo, C. M. Herrera, L. Lopez
Soria, E. W. Schupp, and M. MARQUeZ gave me advice and continuous support. The manuscript benefited from comments by P. HULME.

\section{LITERATURE CITED}

Allison, T. D. 1990. Pollen production and plant density affect pollination and seed production in Taxus canadensis. Ecology 71:516-522.

Bawa, K. S., and C. J. WebB. 1984. Flower, fruit and seed abortion in tropical forest trees: implications for the evolution of paternal and maternal reproductive patterns. Am. J. Bot. 71:736-751.

Dogra, P. D. 1983. Reproductive biology of conifers and its application in forestry and forest genetics. Phytomorphology 33:142-156.

Donoghue, M. J. 1989. Phylogenies and the analysis of evolutionary sequences, with examples from seed plants. Evolution 43:1137-1156.

ECKENWALDER, J. C. 1976. Re-evaluation of Cupressaceae and Taxodiaceae: a proposed merger. Madroño 23:237256.

Fernandes, G. W., and T. G. Whitham. 1989. Selective fruit abscission by Juniperus monosperma as an induced defense against predators. Am. Midl. Nat. 121:389-392.

Freeman, D. C., E. D. McArthur, K. T. HARPer, and A. C. BLAUER. 1981. Influence of environment on the floral sex ratio of monoecious plants. Evolution 35:194-197.

Gagnon, J., J. M. Roth, M. Carroll, R. Hofmann, K. A. Haycock, J. Plamondon, D. S. Feldman, JR., and J. SIMPSON. 1989. SuperAnova: accessible general linear modeling. Abacus Concepts, Berkeley.

GARNOCK-JONES, P. J. 1986. Floret specialization, seed production and gender in Artemisia vulgaris L. (Asteraceae, Anthemideae). Bot. J. Linn. Soc. 92:285-302.

Givnish, T. J. 1980. Ecological constraints on the evolution of breeding systems in seed plants: dioecy and dispersal in gymnosperms. Evolution 34:959-972.

Goldman, D. A., and M. F. Willson. 1986. Sex allocation in functionally hermaphroditic plants: a review and critique. Bot. Rev. 52:157-194.

LeBreton, P. 1983. Nouvelles données sur la distribution au Portugal et en Espagne des sous-espèces du genevrier de Phenicie (Juniperus phoenicea L.). Agronomia Lusit. 42: $55-62$.

LEBRETON, P., and C. LARACine. 1982. Les proanthocyanidines, marqueurs infraspecifiques chez les conifères. Bull. Liason Groupe Polyphenols 12:168-171.

Lebreton, P., and S. Thivend. 1981. Sur une sous-espèce du genévrier de Phenicie Juniperus phoenicea L., definie a partir de critères biochimiques. Naturalia Monspeliensia Ser. Bot. 47:1-12.

LeV-YaduN, S., and N. LiphSChitz. 1987. The ontogeny of gender of Cupressus sempervirens L. Bot. GAz. 148:407412 .
Lloyd, D. G. 1972. Breeding systems in Cotula L. (Compositae, Anthemideae). I. The array of monoclinous and diclinous systems. New Phytol. 71:1181-1194.

- 1979. Parental strategies in angiosperms. N.Z. J. Bot. 17:595-606.

- 1980a. The distributions of gender in four angiosperm species illustrating two evolutionary pathways to dioecy. Evolution 34:123-134.

$1980 b$. Sexual strategies in plants. I. An hypothesis of serial adjustment of maternal investment during one reproductive session. New Phytol. 86:69-79.

. 1981. The distribution of sex in Myrica gale. Plant Syst. Evol. 138:29-45.

- 1982. Variation and evolution of plant species on the outlying islands of New Zealand, with particular reference to Cotula featherstonii. Taxon 31:478-487.

- 1984. Gender allocation in outcrossing cosexual plants. Pages 277-300 in R. Dirzo and J. SARUKHÁN, eds. Perspectives in plant population ecology. Sinauer, Sunderland.

Lloyd, D. G., C. J. Webb, and R. B. Primack. 1980. Sexual strategies in plants. II. Data on the temporal regulation of maternal investment. New Phytol. 86:81-92.

McKone, M. J., and D. W. TonKyn. 1986. Intrapopulation gender variation in common ragweed (Asteraceae: Ambrosia artemisiifolia $\mathrm{L}$.), a monoecious, annual herb. Oecologia (Berl.) 70:63-67.

Owens, J. N., A. M. Colangeli, and S. J. Morris. 1990. The effect of self-pollination, cross-pollination, and no pollination on ovule, embryo, seed, and cone development in Western red-cedar (Thuja plicata). Can. J. Forestry Res. 20:66-75.

Owens, J. N., and M. Molder. 1980. Sexual reproduction in western red cedar (Thuja plicata). Can. J. Bot. 58:13761393.

PrimaCK, R. B., AND D. G. Lloyd. 1980. Andromonoecy in the New Zealand montane shrub manuka, Leptospermum scoparium (Myrtaceae). Am. J. Bot. 67:361-368.

PrIMACK, R. B., and C. MCCALl. 1986. Gender variation in a red maple population (Acer rubrum; Aceraceae): a seven-year study of a "polygamodioecious" species. Am. J. Bot. 73:1239-1248.

Roques, A., J. P. Rimbault, and F. Goussard. 1984. La colonisation des cônes et galbules des genévriers méditerranéens par les insectes et acariens et son influence sur les possibilités de régénération naturelle de ces essences. Ecologia Mediterranea 10:147-169.

SAS INSTITUTE. 1986. SAS user's guide: statistics, version 6.0. SAS Institute, Cary, N.C. 